\title{
$\alpha$-Latrotoxin Releases Calcium in Frog Motor Nerve Terminals
}

\author{
Christopher W. Tsang, Donald B. Elrick, and Milton P. Charlton \\ Department of Physiology, University of Toronto, Toronto, Canada M5S 1 A8
}

$\alpha$-Latrotoxin $(\alpha$-LTX) is a neurotoxin that accelerates spontaneous exocytosis independently of extracellular $\mathrm{Ca}^{2+}$. Although $\alpha$-LTX increases spontaneous transmitter release at synapses, the mechanism is unknown. We tested the hypothesis that $\alpha$-LTX causes transmitter release by mobilizing intracellular $\mathrm{Ca}^{2+}$ in frog motor nerve terminals. Transmitter release was measured electrophysiologically and with the vesicle marker FM1-43; presynaptic ion concentration dynamics were measured with fluorescent ion-imaging techniques. We report that $\alpha$-LTX increases transmitter release after release of a physiologically relevant concentration of intracellular $\mathrm{Ca}^{2+}$. Neither the blockade of $\mathrm{Ca}^{2+}$ release nor the depletion of $\mathrm{Ca}^{2+}$ from endoplasmic reticulum affected $\mathrm{Ca}^{2+}$ signals produced by $\alpha$-LTX. The $\mathrm{Ca}^{2+}$ source is likely to be mitochondria, because the effects on $\mathrm{Ca}^{2+}$ mobilization of CCCP (which depletes mitochondrial $\mathrm{Ca}^{2+}$ ) and of $\alpha$-LTX are mutually occlusive. The release of mitochondrial $\mathrm{Ca}^{2+}$ is partially attributable to an increase in intracellular $\mathrm{Na}^{+}$, suggesting that the mitochondrial $\mathrm{Na}^{+} / \mathrm{Ca}^{2+}$ exchanger is activated. Effects of $\alpha$-LTX were not blocked when $\mathrm{Ca}^{2+}$ increases were reduced greatly in saline lacking both $\mathrm{Na}^{+}$and $\mathrm{Ca}^{2+}$ and by application of intracellular $\mathrm{Ca}^{2+}$ chelators. Therefore, although increases in intracellular $\mathrm{Ca}^{2+}$ may facilitate the effects of $\alpha$-LTX on transmitter release, these increases do not appear to be necessary. The results show that investigations of $\mathrm{Ca}^{2+}$. independent $\alpha$-LTX mechanisms or uses of $\alpha$-LTX to probe exocytosis mechanisms would be complicated by the release of intracellular $\mathrm{Ca}^{2+}$, which itself can trigger exocytosis.

Key words: $\alpha$-latrotoxin; presynaptic toxin; mitochondria; calcium; sodium; exocytosis; frog neuromuscular junction/motor nerve terminal
Neurotoxins are important tools for studying synaptic physiology. $\alpha$-Latrotoxin ( $\alpha$-LTX) is a neurotoxin isolated from the venom of the black widow spider, Latrodectus mactans tredecimguttatus. At the frog neuromuscular junction (NMJ) $\alpha$-LTX increases the frequency of spontaneous transmitter release independently of extracellular $\mathrm{Ca}^{2+}$ (Longenecker et al., 1970) despite the fact that $\mathrm{Ca}^{2+}$ influx is required for nerve-evoked transmitter release (Bennett, 1999). This implies that there might be a mechanism of transmitter release that could bypass the requirement for $\mathrm{Ca}^{2+}$.

Two theories have been proposed to explain how $\alpha$-LTX could increase transmitter release independently of extracellular $\mathrm{Ca}^{2+}$. The first suggests that $\alpha$-LTX forms pores in nerve terminals and that changes in ion conductance could mediate its effect on transmitter release. This idea is supported by the fact that $\alpha$-LTX can form nonselective cation pores in lipid bilayer membranes (Finkelstein et al., 1976) by oligomerizing into homotetrameric structures (Orlova et al., 2000). However, this mechanism alone cannot explain the specificity of $\alpha$-LTX for presynaptic nerve terminals (Valtorta et al., 1984). A second theory suggests that $\alpha$-LTX interacts with a membrane receptor and that activation of a signal transduction mechanism triggers vesicle release. This theory was strengthened when two distinct receptors with nanomolar affinity for $\alpha$-LTX were isolated and cloned. One is the single-transmembranedomain cell surface receptor neurexin-I $\alpha$ (Ushkaryov et al., 1992), and the other is a seven-transmembrane-domain G-protein-coupled receptor, latrophilin/CIRL (Krasnoperov et al., 1997; Lelianova et al., 1997), expressed here as CL1. The latter is thought to mediate the actions of $\alpha$-LTX in the absence of extracellular $\mathrm{Ca}^{2+}$ because $\alpha$-LTX binding to neurexin is $\mathrm{Ca}^{2+}$-dependent (Davletov et al., 1995), but binding to CL1 does not require $\mathrm{Ca}^{2+}$ (Davletov et al., 1996). Studies with truncated CL1 mutants transfected into chromaffin cells, however, have demonstrated that receptor activation is

Received June 15, 2000; revised Sept. 5, 2000; accepted Sept. 6, 2000.

This research work was supported by a grant to M.P.C. from the Medical Research Council of Canada and scholarships to C.W.T. from the Department of Physiology, University of Toronto and the Ontario Ministry of Education.

Correspondence should be addressed to Dr. Milton P. Charlton, Medical Sciences Building, Room 3232, Department of Physiology, University of Toronto, 1 Kings College Circle, Toronto, ON, Canada M5S 1A8. E-mail: milton@spine.med. utoronto.ca.

Copyright (C) 2000 Society for Neuroscience $\quad 0270-6474 / 00 / 208685-08 \$ 15.00 / 0$ not required for transmitter release by $\alpha$-LTX (Sugita et al., 1998). Therefore, it seems likely that $\alpha$-LTX is targeted to presynaptic nerve terminals by the receptor, where it then proceeds to act independently of the receptor; this function could include pore formation.

The mechanism of $\alpha$-LTX action has been difficult to resolve, and inconsistent results are seen in different cell types. For example, transmitter release by $\alpha$-LTX is dependent on $\mathrm{Ca}^{2+}$ mobilization in rat brain synaptosomes (Davletov et al., 1998; Rahman et al., 1999), whereas in secretory cell lines such as PC12 cells or $\beta$-pancreatic cells no changes in intracellular $\mathrm{Ca}^{2+}$ are observed in the presence of $\alpha$-LTX (Meldolesi et al., 1984).

$\alpha$-LTX has been used widely under the assumption that it is a $\mathrm{Ca}^{2+}$-independent secretagogue at the frog NMJ. However, this assumption has not been tested with $\mathrm{Ca}^{2+}$ detection methods. Release of intracellular $\mathrm{Ca}^{2+}$ easily could explain the actions of $\alpha$-LTX in the absence of extracellular $\mathrm{Ca}^{2+}$. Therefore, we decided to test the hypothesis that at frog motor nerve terminals $\alpha$-LTX causes $\mathrm{Ca}^{2+}$ mobilization from intracellular stores and that this triggers transmitter release.

\section{MATERIALS AND METHODS}

Animals and experimental treatment. Rana pipiens (leopard) frogs $(4-5 \mathrm{~cm}$ body length; Wards Scientific, St. Catherine's, Ontario) were housed at $15^{\circ} \mathrm{C}$ in cages with a flow-through water system. Frogs were double-pithed, and the cutaneous pectoris muscles with the innervating pectoralis propius nerve were dissected out (Dreyer and Peper, 1974). Excised muscles were pinned down in a Sylgard-coated (Dow Corning, Midland, MI) preparation dish and maintained at room temperature $\left(20-22^{\circ} \mathrm{C}\right)$ in normal physiological saline (NPS) containing (in $\mathrm{mM}$ ) $120 \mathrm{NaCl}, 2 \mathrm{KCl}, 1$ $\mathrm{NaHCO}_{3}, 1.8 \mathrm{CaCl}_{2}$, and $5 \mathrm{HEPES}$, pH-adjusted to 7.2 with $\mathrm{NaOH}$.

Experimental solutions. $\mathrm{Ca}^{2+}$-free saline (CFS) containing (in $\mathrm{mM}$ ) 120 $\mathrm{NaCl}, 2 \mathrm{KCl}, 1 \mathrm{NaHCO}_{3}, 5 \mathrm{MgCl}_{2}, 10 \mathrm{HEPES}$, and $5 \mathrm{EGTA}$, pH-adjusted to 7.2 with $\mathrm{NaOH}$, was used to study the actions of $\alpha$-LTX in the absence of extracellular $\mathrm{Ca}^{2+}$. When $\mathrm{Na}^{+}$and $\mathrm{Ca}^{2+}$ were not required, a Na${ }^{+}$. and $\mathrm{Ca}^{2+}$-free saline (NCFS) was made containing (in mM) 120 choline$\mathrm{Cl}^{-}, 5 \mathrm{MgCl}_{2}, 10 \mathrm{HEPES}$, and 5 BAPTA tetrapotassium salt (Molecular Probes, Eugene, OR), pH-adjusted to 7.2 with $\mathrm{KOH}$. Before the start of any experiment that required the removal of an ion, preparations were washed (in CFS or NCFS) with four to five bath changes every $10 \mathrm{~min}$ for 1 hr. All saline salts and buffers were purchased from Sigma (St. Louis, MO). For BAPTA-AM experiments a $5 \mathrm{~mm}$ stock concentration of BAPTA-AM was made up in dimethylsulfoxide (DMSO; Sigma) and diluted 1:50 to get a working concentration of $100 \mu \mathrm{M}$. A $1 \mathrm{M}$ stock concentration of probenecid (Sigma) was made up in ethanol and diluted 
1:1000 to get a working concentration of $1 \mathrm{~mm}$. Pluronic acid (Molecular Probes) was added to assist in the solubilization of probenecid and BAPTA-AM. A working concentration of $2 \mu \mathrm{M}$ pluronic acid was achieved by diluting a $1 \mathrm{~mm}$ stock in DMSO to 1:1000. The final solution was mixed by sonication for several seconds.

Dye loading. Nerve terminals were loaded with the fluorescent dyes Oregon green 488 BAPTA-1-dextran or sodium green-dextran (Molecular Probes; 10,000 molecular weight) for measuring changes in presynaptic $\mathrm{Ca}^{2+}$ or $\mathrm{Na}^{+}$, respectively, by forward-filling the dye through the cut end of the innervating motor nerve. The muscles were washed first in a Petri dish with CFS for $10 \mathrm{~min}$ to remove excess $\mathrm{Ca}^{2+}$. With a pair of sharp scissors the motor nerve was cut $\sim 1 \mathrm{~cm}$ proximal to the muscle in a CFS bath. Then the preparation was transferred to a $1.5 \mathrm{ml}$ rectangular well (containing CFS) that was cut out of a Sylgard-coated Petri dish. An adjacent small well contained $1 \mu \mathrm{l}$ of the dye indicator at a concentration of $5 \mathrm{~mm}$ (in distilled water). The freshly cut end of the nerve was drawn into the dye-filled well, and a Vaseline border was made to isolate the contents of the two wells. Once the CFS was replaced with NPS, the dish was sealed with Parafilm (American National Can, Greenwich, CT) and stored at $15^{\circ} \mathrm{C}$ for $12-20 \mathrm{hr}$. During the incubation period the indicators were taken up by the axons and carried to the nerve terminals.

For FM1-43 (Molecular Probes) imaging the muscles were incubated with the dye $(2 \mu \mathrm{M})$ in NPS for $15 \mathrm{~min}$. During this incubation period the nerve was stimulated with 100 pulses $(5 \mathrm{sec}$ at $20 \mathrm{~Hz})$ every $30 \mathrm{sec}$ to induce vesicle recycling and uptake of the dye. Once the vesicles were loaded with FM1-43, the preparation was washed thoroughly with NPS to remove any extracellular and nonspecifically bound dye.

Blockade of spontaneous action potentials and postjunctional receptors. In CFS, spontaneous firing of action potentials can cause muscle fibers to twitch and also can load nerve terminals with $\mathrm{Na}^{+}$. The latter is known to have a physiological effect on transmitter release (Zengel et al., 1994). Therefore, the firing of spontaneous action potentials was blocked by the addition of $4 \mu \mathrm{M}$ tetrodotoxin (TTX; Sigma) to block $\mathrm{Na}^{+}$channels.

When recording miniature endplate potentials (MEPPs) and intracellular $\mathrm{Ca}^{2+}$ fluorescence in NPS, we used $\mu$-conotoxin GIIIA $(10 \mu \mathrm{g} / \mathrm{ml}$; Bachem, Torrance, CA) to block muscle $\mathrm{Na}^{+}$channels (Sosa and Zengel, 1993). This allowed us to block muscle contractions but preserved nerve action potentials and MEPPs. When only fluorescence imaging was required, $\alpha$-bungarotoxin $(5 \mu \mathrm{g} / \mathrm{ml})$, which blocks nicotinic receptors, was used instead to block muscle contractions. TTX was added to the bath when, subsequently, the muscles were transferred to CFS.

Electrophysiology. Transmitter release was monitored by intracellular recordings in a muscle fiber via 5-15 $\mathrm{M} \Omega$ glass microelectrodes (World Precision Instruments, Everett, WA) filled with $3 \mathrm{M} \mathrm{KCl}$. Transmitter release was evoked by stimulating the motor nerve $(0.2 \mathrm{~Hz})$ at twice the threshold voltage that was required for muscle contraction in NPS. Responses were amplified (Neuroprobe amplifier, AM Systems, Carlsborg, WA), digitized (10 kHz, 12 bit; Labmaster interface, Scientific Solutions, Solon, $\mathrm{OH}$ ), and averaged in groups of three to five by TOMAHACQ (T. A. Goldthorpe, University of Toronto), a program for PC data acquisition systems. Concurrently, a digital recording of the experiment (VR-10 digital data recorder, Instrutech, Great Neck, NY) was made for later analysis of MEPP frequency.

MEPP records stored on tapes were digitized by a Digidata 1200 Interface A/D Converter (Axon Instruments, Foster City, CA) that used Axoscope (Axon Instruments) data acquisition software and were analyzed with Mini Analysis software v4.0.1 (Synaptosoft, Leonia, NJ). MEPPs were counted by hand, and the frequency was calculated from the time that was required to record 100 MEPPs. During the height of $\alpha$-LTX action the frequency of quantal release is so high that it is difficult to count MEPPs accurately. Therefore, MEPPs were counted when there was a positive inflection of the membrane potential that was greater than the level of noise. Although this method underestimated the frequency of spontaneous transmitter release during toxin action, the absolute frequency was not essential for any of the hypotheses that were tested here. Any treatment that attenuated the action of $\alpha$-LTX by $>50 \%$ was considered to have a significant effect.

Fluorescence imaging. Dye-loaded nerve terminals located on surface fibers were chosen for all experiments. Fluorescence $(F)$ was measured with a Bio-Rad 600 (Hercules, CA) confocal laser-scanning microscope that used $1 \%$ of the maximum laser intensity for the ion indicators. Oregon green and sodium green dyes were excited by using the $488 \mathrm{~nm}$ line of the argon ion laser, and the emitted fluorescence was detected via a low-pass filter with a $515 \mathrm{~nm}$ cutoff. Confocal images were acquired by using a $40 \times$ water-dipping objective ( 0.55 numerical aperture; Nikon) and were averaged in groups of three.

Confocal images were acquired digitally with data acquisition software provided by Bio-Rad. Image files were analyzed later with BFOCAL, a program for PC analysis of Bio-Rad images written by T. A. Goldthorpe (University of Toronto). Changes in fluorescence were measured from a region of interest on the nerve terminal, which displayed the greatest dynamic range after nerve stimulation, and were expressed as:

$$
\% \Delta F / F=\left[\left[F_{\text {response }}-F_{\text {resting }}\right] / F_{\text {resting }}\right] \times 100 \% .
$$

Fluorescence images also were captured by using a Nikon Optiphot microscope equipped with a $40 \times(0.55$ numerical aperture; Nikon $)$ waterdipping objective, xenon lamp, and CCD camera (Cohu 4915) for FM1-43 experiments. Changes in fluorescence were processed with Axon Imaging Workbench software (Axon Instruments) and expressed as $\% \Delta F / F$ (see above). Measurements were made from several clusters of vesicles at $2 \mathrm{~min}$ intervals and adjusted by background subtraction.

Chemicals. CCCP (carbonyl cyanide $m$-chlorophenylhydrazone) and thapsigargin were purchased from Calbiochem (San Diego, CA). BAPTA-AM was purchased from Molecular Probes, and $\alpha$-LTX was bought from Latoxan (Valence, France).

Statistical analysis and figures. All values are reported as the mean \pm SEM. An independent Student's $t$ test was used to determine statistical significance at a $95.0 \%$ confidence level. $N, n$ refers to the number of muscles (i.e., preparations) and the number of endplates, respectively. SigmaPlot 4 graphing software (Jandel Scientific, San Rafael, CA) and Corel Draw 8 (Corel, Ottawa, Canada) were used to graph and display the data.

\section{RESULTS}

\section{$\alpha$-LTX increases intracellular $\mathrm{Ca}^{2+}$ and transmitter release}

In normal physiological saline, stimulation of the motor nerve at 10 $\mathrm{Hz}$ for $5 \mathrm{sec}$ produced a rapid rise in $\mathrm{Ca}^{2+}$ fluorescence of $40 \pm$ $2 \%$ above baseline $(N, n=7,7$; Fig. $1 A)$. Increasing the stimulation frequency to 20 and $40 \mathrm{~Hz}$ produced larger $\mathrm{Ca}^{2+}$ signals $(72 \pm 1$ and $107 \pm 1 \%$, respectively; $N, n=7,7$ for both) because of the more frequent opening of voltage-gated $\mathrm{Ca}^{2+}$ channels (Robitaille and Charlton, 1992). This control was performed for every nerve terminal that we examined to demonstrate the dynamic range of the indicator and detection system.

$\mathrm{Ca}^{2+}$ was removed by washing the preparations with CFS (see Materials and Methods). When the nerve was restimulated with 10 , 20, and $40 \mathrm{~Hz}$ stimulation in CFS (Fig. $1 A$ ), no $\mathrm{Ca}^{2+}$ signals were produced ( $N, n=7,7$ for each stimulation frequency). This suggests that the bath was nominally free of unchelated $\mathrm{Ca}^{2+}$ and that any changes in intracellular $\mathrm{Ca}^{2+}$ by $\alpha$-LTX could not be attributable to $\mathrm{Ca}^{2+}$ entry.

When $\alpha$-LTX (0.5 nM) was applied to nerve terminals bathed in CFS, the average change in $\mathrm{Ca}^{2+}$ fluorescence was $55 \%$ (Table 1). Figure $1 B$ shows a typical result in which there was $\sim 62 \%$ increase in fluorescence. The increase in $\mathrm{Ca}^{2+}$ fluorescence with the application of $0.5 \mathrm{nM} \alpha$-LTX was similar to that produced by $10 \mathrm{~Hz}$ nerve stimulation in NPS (Fig. $1 A$ ). $\mathrm{Ca}^{2+}$ signals were not significantly different when a 10 -fold higher concentration of $\alpha$-LTX (5 nM) was applied $(50 \pm 6 \% ; N, n=6,6)$. Unlike nerve stimulation, which increased intracellular $\mathrm{Ca}^{2+}$ by $\mathrm{Ca}^{2+}$ entry, $\alpha$-LTX increased intracellular $\mathrm{Ca}^{2+}$ by $\mathrm{Ca}^{2+}$ mobilization from intracellular stores. The time course of $\mathrm{Ca}^{2+}$ elevation by $\alpha$-LTX is much slower than that obtained with nerve stimulation (several minutes compared with a few seconds).

Slightly after elevating the intracellular $\mathrm{Ca}^{2+}$ concentration, $\alpha$-LTX also caused a gross increase in spontaneous transmitter release as MEPP frequency increased from 1-2 to 3-400 MEPPs/ sec (Fig. $1 B$ ). Then, over the course of $10 \mathrm{~min}$, the frequency of spontaneous transmitter release declined to low levels $(<1 \mathrm{MEPP} /$ $\mathrm{sec}$ ). The run-down in MEPP frequency is attributable to synaptic vesicle depletion (Clark et al., 1970, 1972), because vesicle recycling does not occur in CFS after treatment with $\alpha$-LTX (Ceccarelli and Hurlbut, 1980; Henkel and Betz, 1995).

\section{$\alpha$-LTX does not mobilize $\mathrm{Ca}^{2+}$ from endoplasmic reticulum (ER)}

CL1 has been classified as a seven-transmembrane receptor coupled to the G-protein, $\mathrm{G} \alpha_{\mathrm{q} / 11}$ (Rahman et al., 1999). This G-protein can activate phospholipase C (PLC) to produce inositol trisphosphate $\left(\mathrm{IP}_{3}\right)$, which mobilizes $\mathrm{Ca}^{2+}$ from the ER. Therefore, the PLC inhibitor U-73122 was used to determine whether the activation of PLC was responsible for the action of $\alpha$-LTX on transmitter release and $\mathrm{Ca}^{2+}$ mobilization. Nerve-muscle preparations were incubated with U-73122 $(50 \mu \mathrm{M})$ for $1 \mathrm{hr}$ in CFS, and then $\alpha$-LTX $(0.5 \mathrm{nM})$ was applied. In the presence of U-73122, $\alpha$-LTX still increased MEPP frequency and intracellular $\mathrm{Ca}^{2+}$ similar to controls (Fig. $2 A$, Table 1 ).

We next tried to inhibit the release of $\mathrm{Ca}^{2+}$ from ER by first depleting the store with thapsigargin. When thapsigargin 

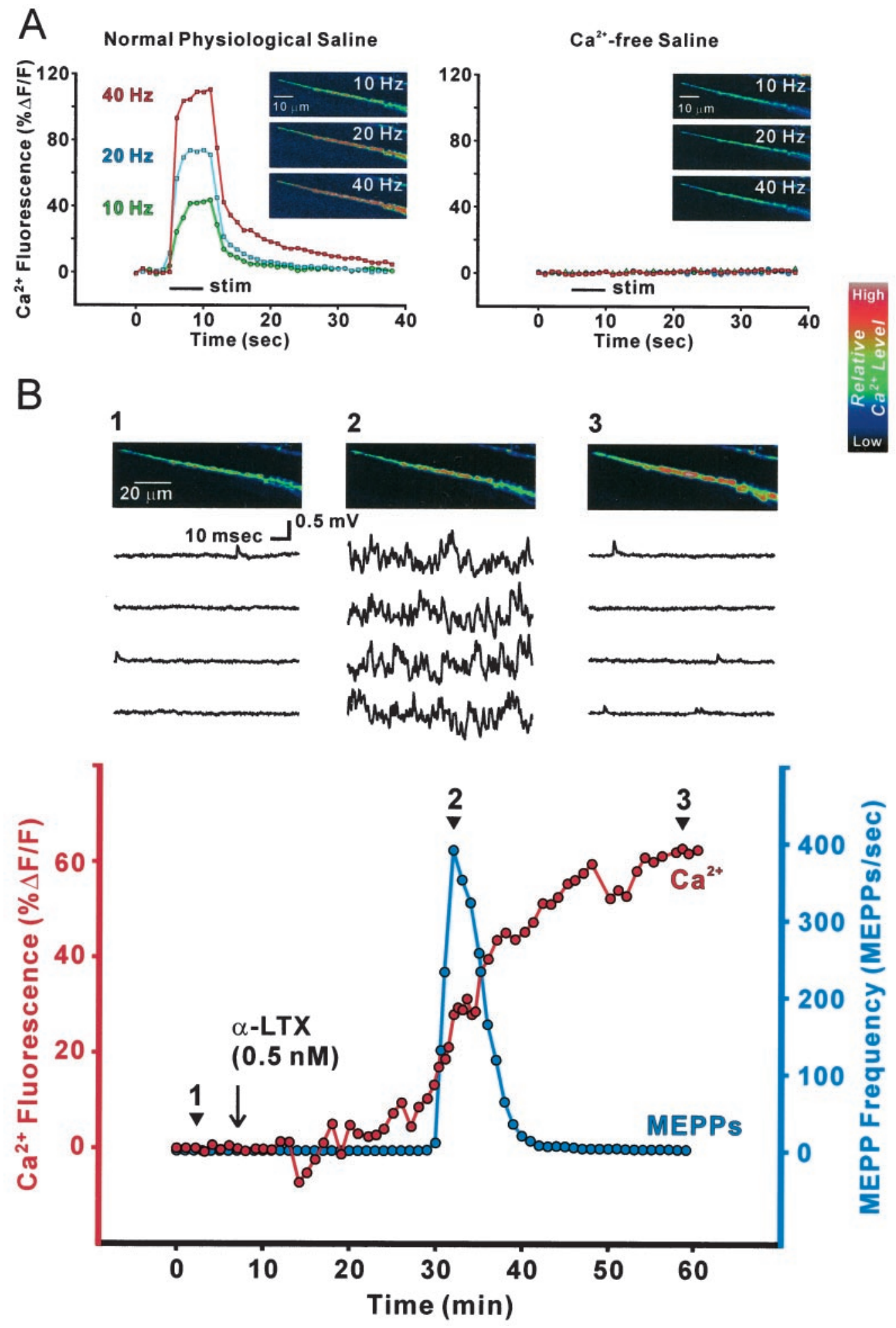

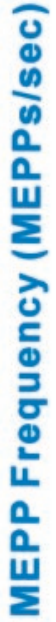

Figure 1. Effect of $\alpha$-LTX on transmitter release and presynaptic $\mathrm{Ca}^{2+}$ in $\mathrm{Ca}^{2+}$-free saline. $A$, Left, Presynaptic intracellular $\mathrm{Ca}^{2+}$ signals in NPS in response to 10,20 , and $40 \mathrm{~Hz}$ nerve stimulation. A, Right, Absence of presynaptic $\mathrm{Ca}^{2+}$ signals in CFS in response to the same stimulation frequencies. The motor nerve was stimulated for $5 \mathrm{sec}$ at twice the voltage that was required for muscle contraction. Inset pictures show indicator fluorescence in the presynaptic terminal at the peak of the response at each frequency of stimulation. Similar results were obtained in seven preparations. $B$, The bottom graph shows measurements from a simultaneous recording of spontaneous quantal transmitter release frequency (MEPP frequency, blue) and $\mathrm{Ca}^{2+}$ fluorescence (red) in the same motor nerve terminal as in $A$ after treatment with $0.5 \mathrm{nM} \alpha$-LTX (arrow). Pictures of nerve terminal fluorescence and MEPP recordings are given at three time points during the experiment (1-3, top panels). The intracellular $\mathrm{Ca}^{2+}$ concentration increased before the increase in transmitter release. All of the data in this figure are from a single endplate. Similar results were obtained in two other experiments that recorded MEPPs and intracellular $\mathrm{Ca}^{2+}$ simultaneously.

$(20 \mu \mathrm{M})$ was applied to nerve terminals bathed in CFS for $1 \mathrm{hr}$, there was very little change in the intracellular $\mathrm{Ca}^{2+}$ concentration (Fig. 2B) or transmitter release (Table 1). However, when $\alpha$-LTX $(0.5 \mathrm{nM})$ was applied after thapsigargin, a significant increase in $\mathrm{Ca}^{2+}$ fluorescence (Fig. $2 B$ ) and an acceleration of spontaneous transmitter release were still observed $(\mathrm{Ta}-$ ble 1). Although $\mathrm{Ca}^{2+}$ in ER stores can have subtle physiological effects at the frog NMJ (Narita et al., 1998), our data suggest that it is not sufficient to support the actions of $\alpha$-LTX in CFS. Therefore, ER is probably not the primary $\mathrm{Ca}^{2+}$ pool affected by $\alpha$-LTX.

\section{$\alpha$-LTX mobilizes $\mathrm{Ca}^{2+}$ from mitochondria}

Another major $\mathrm{Ca}^{2+}$-storing organelle found in nerve terminals is the mitochondrion. Unlike ER, these stores may not be depleted readily in CFS because of the large internally negative membrane potential $(\sim 150-200 \mathrm{mV})$ opposing the efflux of $\mathrm{Ca}^{2+}$. Several drugs, such as CCCP, are well known to interfere with mitochondrial metabolism and can cause mitochondria to lose their $\mathrm{Ca}^{2+}$. When CCCP $(10 \mu \mathrm{M})$ was applied to nerve terminals bathed in CFS, a significant rise in intracellular $\mathrm{Ca}^{2+}(50 \pm 12 \% ; N, n=5,5)$ and transmitter release $(102 \pm 4 \mathrm{MEPPs} / \mathrm{sec} ; N, n=3,3)$ was 
Table 1. Summary of drug effects on the actions of $\alpha$-LTX

\begin{tabular}{lclll} 
Treatment & $\mathrm{Ca}^{2+}$ Fluorescence $(\% \Delta F / F \pm \mathrm{SEM})$ & MEPP Frequency $(\mathrm{MEPPs} / \mathrm{sec} \pm \mathrm{SEM})$ \\
\hline$\alpha$-LTX $(0.5 \mathrm{nM})$ & $55 \pm 9$ & $(N, n=9,10)$ & $340 \pm 19$ & $(N, n=5,5)$ \\
$\alpha$-LTX $(0.5 \mathrm{nM})$ after U-73122 $(50 \mu \mathrm{M})$ & $54 \pm 6$ & $(N, n=4,7 ; p=0.76)$ & $353 \pm 8$ & $(N, n=3,3 ;$ similar to $0.5 \mathrm{nM} \alpha$-LTX) \\
Thapsigargin $(20 \mu \mathrm{M})$ & $16 \pm 7$ & $\left(N, n=2,3 ; p=0.04^{*}\right)$ & $3.5 \pm 2$ & $(N, n=3,3)$ \\
$\alpha$-LTX $(0.5 \mathrm{nM})$ after thapsigargin $(20 \mu \mathrm{M})$ & $60 \pm 17$ & $(N, n=2,3 ; p=0.5)$ & $359 \pm 11$ & $(N, n=2,2 ;$ similar to $0.5 \mathrm{nM} \alpha$-LTX) \\
$\alpha$-LTX $(0.5 \mathrm{nM})$ after CCCP $(10 \mu \mathrm{M})$ & $2.4 \pm 1$ & $\left(N, n=3,3 ; p=0.00005^{*}\right)$ & - & \\
CCCP $(10 \mu \mathrm{M})$ & $50 \pm 12$ & $(N, n=5,5 ; p=0.74)$ & $102 \pm 4$ & $(N, n=3,3 ;$ lower than $0.5 \mathrm{nM} \alpha$-LTX) \\
$\operatorname{CCCP}(10 \mu \mathrm{M})$ after $\alpha$-LTX $(0.5 \mathrm{nM})$ & $1.3 \pm 1$ & $\left(N, n=4,4 ; p=0.01^{*}\right)$ & - &
\end{tabular}

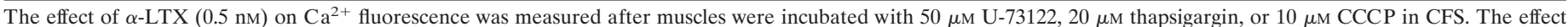

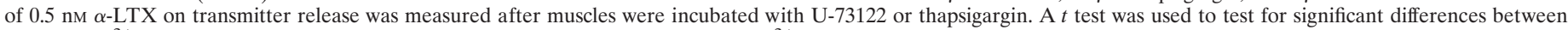

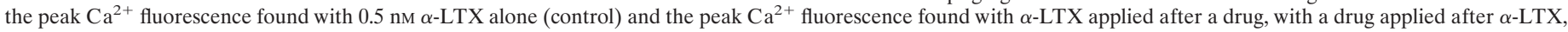

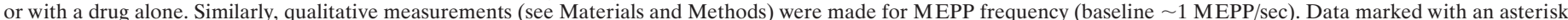

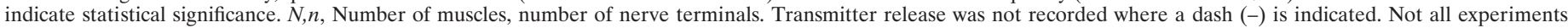
measured fluorescence and MEPP frequency simultaneously.

Figure 2. The effect of U73122 and thapsigargin on $\alpha$-LTX-induced Ca ${ }^{2+}$ mobilization. Nerve terminals were bathed first in CFS containing $4 \mu \mathrm{M}$ TTX for $1 \mathrm{hr}$. Then changes in intracellular $\mathrm{Ca}^{2+}$ were measured after the addition of $50 \mu \mathrm{M}$ $\mathrm{U}-73122(A)$ or $20 \mu \mathrm{M}$ thapsigargin $(B)$, followed by $0.5 \mathrm{nM} \alpha$-LTX 1 hr later. Similar results were observed from six other U-73122-treated nerve terminals and two other thapsigargin-treated nerve terminals (see Table 1). Neither drug prevented the release of intracellular $\mathrm{Ca}^{2+}$ by $\alpha$-LTX.
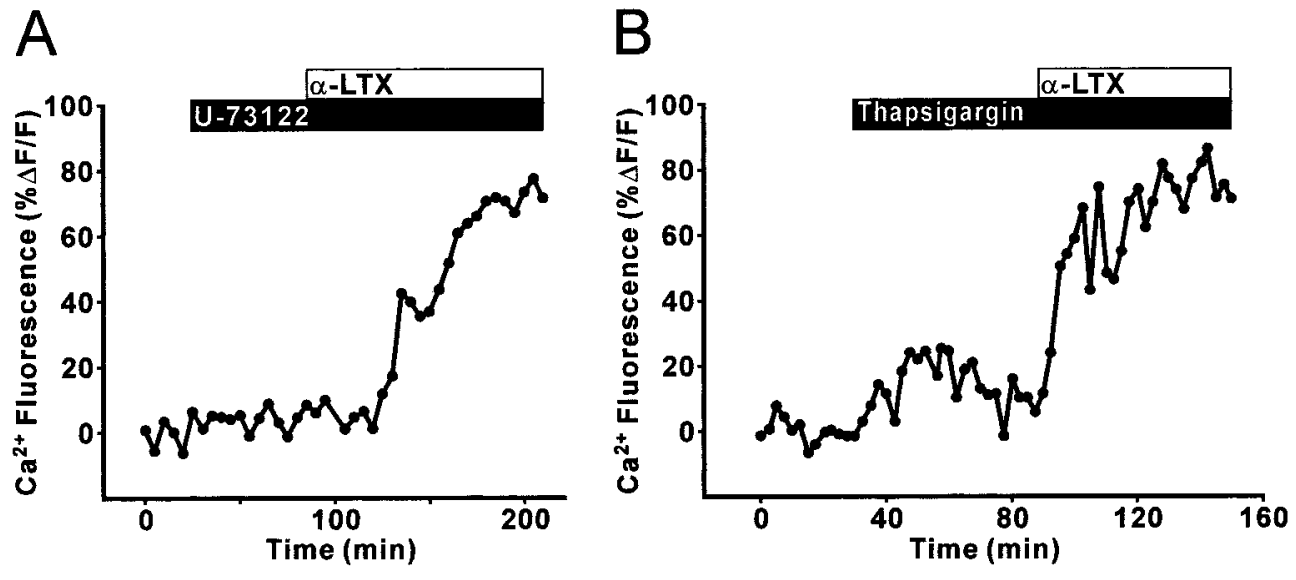

produced (Table 1). The amount of $\mathrm{Ca}^{2+}$ mobilized by CCCP on average was not significantly different from that mobilized by $\alpha$-LTX (Table 1), suggesting that mitochondria are likely to be the $\mathrm{Ca}^{2+}$ source.

To determine whether $\alpha$-LTX mobilizes $\mathrm{Ca}^{2+}$ from mitochondria, we first used CCCP $(10 \mu \mathrm{M})$ to deplete mitochondrial $\mathrm{Ca}^{2+}$ stores from nerve terminals bathed in CFS. This was done in the presence of oligomycin $(10 \mu \mathrm{g} / \mathrm{ml})$, which prevents the reverse action of the mitochondrial ATPase from consuming ATP (Budd and Nicholls, 1996). Oligomycin on its own had no effect on $\mathrm{Ca}^{2+}$ homeostasis (data not shown). Once the $\mathrm{Ca}^{2+}$ signal had stabilized after the addition of CCCP, the addition of $\alpha$-LTX ( $0.5 \mathrm{nM})$ did not produce any further increase in intracellular $\mathrm{Ca}^{2+}(2.4 \pm 1 \%$; $N, n=3,3$; Fig. $3 A$ ). Similarly, when nerve terminals bathed in CFS were pretreated with $\alpha$-LTX $(0.5 \mathrm{nM})$, the addition of CCCP $(10$ $\mu \mathrm{M})$ produced no further change in intracellular $\mathrm{Ca}^{2+}(1.3 \pm 1 \%$; $N, n=4,4$; Fig. $3 B$ ). Because the effects of CCCP and $\alpha$-LTX on $\mathrm{Ca}^{2+}$ mobilization were mutually occlusive, this suggests that $\alpha$-LTX targets mitochondrial $\mathrm{Ca}^{2+}$ pools. In both cases, further increases in the $\mathrm{Ca}^{2+}$ signal were not prevented as a result of dye saturation because the dynamic range of the dye, determined before the experiment by nerve stimulation in NPS (see Fig. 1A), was on average at least two times larger than the $\mathrm{Ca}^{2+}$ signal produced by $\alpha$-LTX or CCCP. Furthermore, replacing the bath with NPS at the end of the experiment rapidly produced a much larger $\mathrm{Ca}^{2+}$ signal than that produced by any combination of CCCP and $\alpha$-LTX (Fig. 3A,B). Both of these observations indicate that larger $\mathrm{Ca}^{2+}$ signals could have been detected in these occlusion experiments. The $\mathrm{Ca}^{2+}$ signal produced by adding $\mathrm{Ca}^{2+}$ back to the bath was insensitive to the $\mathrm{Ca}^{2+}$ channel blocker $\mathrm{Cd}^{2+}(100$ $\mu \mathrm{M} \mathrm{CaCl}{ }_{2}$ added to saline; data not shown). This suggests that $\mathrm{Ca}^{2+}$ must have entered through toxin-induced pores and not through $\mathrm{Ca}^{2+}$ channels.
It is possible that stimulus-dependent $\mathrm{Ca}^{2+}$ entry during the experiment may have caused mitochondria to accumulate $\mathrm{Ca}^{2+}$. Similarly, it is possible that, during the long incubation to allow dye transport to terminals, mitochondria accumulated $\mathrm{Ca}^{2+}$ to the extent that the results are an artifact of the incubation time. To examine these possibilities, we avoided the long incubation time by loading the dye for only $3 \mathrm{hr}$ at room temperature into nerves cut close to the muscle. Furthermore, the nerve was left unstimulated for the duration of the experiment, and $4 \mu \mathrm{M}$ TTX was added to prevent spontaneous nerve activity. When $10 \mu \mathrm{M}$ CCCP was applied to nerve terminals bathed in CFS, a large $\mathrm{Ca}^{2+}$ signal was produced $(155 \pm 1 \% ; N, n=1,5)$. Because this signal is greater than the signal produced by the terminals incubated overnight and by stimulation during the experiment, we conclude that $\mathrm{Ca}^{2+}$ release by mitochondria is not an artifact of incubation time or nerve-evoked activity.

\section{$\mathrm{Ca}^{2+}$ mobilization by $\alpha$-LTX is $\mathrm{Na}^{+}$-dependent}

We next asked how $\alpha$-LTX signals the mitochondria to release $\mathrm{Ca}^{2+}$. Because $\alpha$-LTX forms a pore in frog nerve terminals (Davletov et al., 1998), we tested the hypothesis that $\mathrm{Na}^{+}$entry through this pore causes mitochondria to lose $\mathrm{Ca}^{2+}$. It has been shown previously that methods that increase intracellular $\mathrm{Na}^{+}$at nerve terminals also cause an increase in transmitter release (Baker and Crawford, 1975; Meiri et al., 1981; Atwood et al., 1983). To determine whether $\alpha$-LTX increases intracellular $\mathrm{Na}^{+}$, we detected changes in the intracellular $\mathrm{Na}^{+}$concentration with the fluorescent indicator sodium green-dextran loaded in nerve terminals that were bathed in CFS. Application of $\alpha$-LTX $(0.5 \mathrm{nM})$ caused the $\mathrm{Na}^{+}$signal to increase by $42 \pm 4 \%(N, n=5,5)$. Similar responses were observed with $5 \mathrm{~nm} \alpha$-LTX (Fig. $4 A$ ). Entry of $\mathrm{Na}^{+}$, however, was not attributable to the opening of voltage-gated $\mathrm{Na}^{+}$channels because these were blocked by $4 \mu \mathrm{M}$ TTX. 

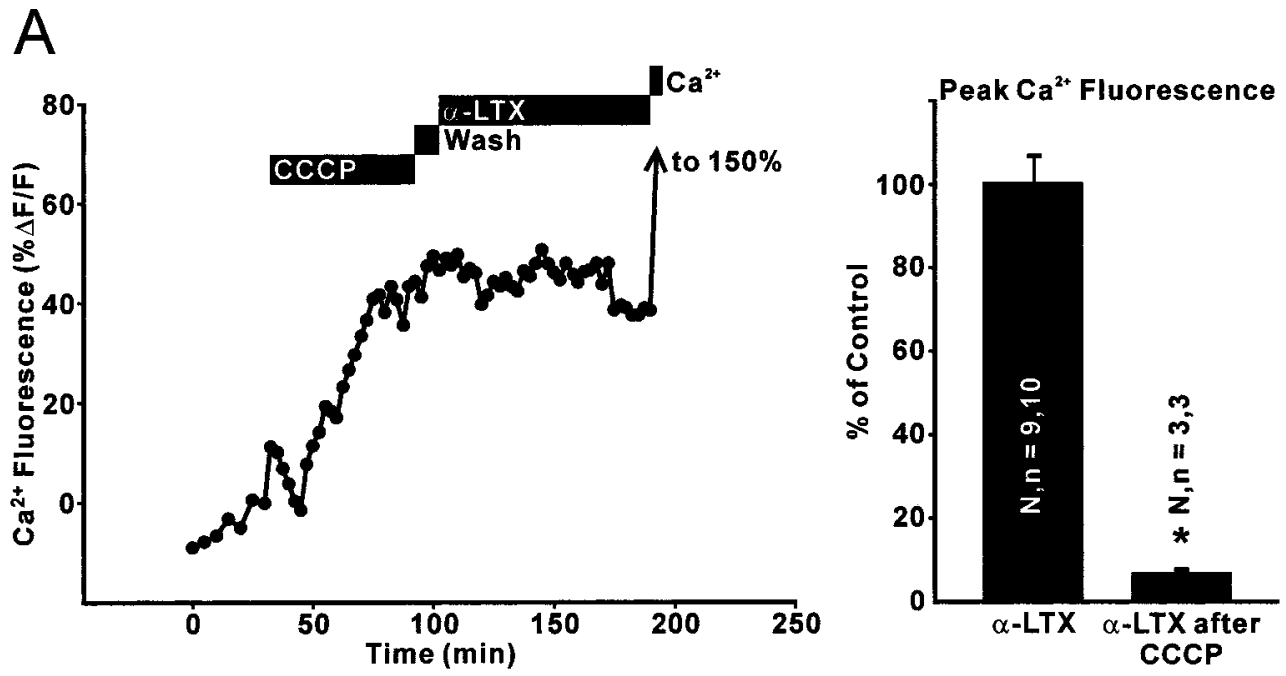

B

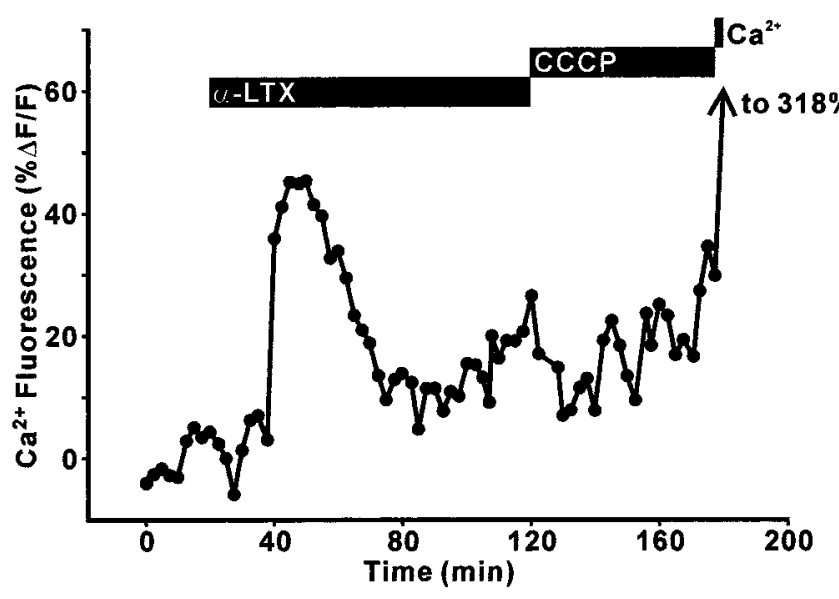

Figure 3. $\mathrm{CCCP}$ and $\alpha$-LTX release $\mathrm{Ca}^{2+}$ from the same store. A, Left, Change in $\mathrm{Ca}^{2+}$ fluorescence when $\alpha$-LTX was applied after $10 \mu \mathrm{M}$ CCCP, followed by $0.5 \mathrm{nM} \alpha$-LTX to a nerve terminal bathed in CFS with $4 \mu \mathrm{M}$ TTX and $10 \mu \mathrm{g} / \mathrm{ml}$ oligomycin. There was a $10 \mathrm{~min}$ wash period (Wash) with CFS between the application of CCCP and $\alpha$-LTX. When NPS (i.e., containing $1.8 \mathrm{~mm} \mathrm{Ca}^{2+}$ ) was applied $\left(\mathrm{Ca}^{2+}\right)$ after $\alpha$-LTX, there was a large increase in $\mathrm{Ca}^{2+}$ fluorescence. $A$, Right, Bar graph compares the additional average peak $\mathrm{Ca}^{2+}$ fluorescence achieved when $\alpha$-LTX was applied after CCCP [i.e., $(\Delta F / F)_{\alpha \text {-LTX }}+\operatorname{CCCP}=\left(\left[F_{\alpha-}\right.\right.$ $\left.\mathrm{LTX}+\mathrm{CCCP}] / F_{\text {rest }}\right)-\left(\left[F_{\mathrm{CCCP}}-F_{\text {rest }}\right] /\right.$ $\left.\left.F_{\text {rest }}\right)\right]$ with the average peak $\mathrm{Ca}^{2+}$ fluorescence achieved when $\alpha$-LTX was applied alone in other experiments [i.e., $\left.\Delta F / F_{\alpha \text {-LTX }}=\left(\left[F_{\alpha \text {-LTX }}-F_{\text {rest }}\right] / F_{\text {rest }}\right)\right]$. The value for $\Delta F / F_{\alpha \text {-LTX }}$ was normalized to $100 \%$. An asterisk indicates a significant difference in $\mathrm{Ca}^{2+}$ fluorescence relative to control. $B$, Change in $\mathrm{Ca}^{2+}$ fluorescence when CCCP was applied after $\alpha$-LTX. The bar graph comparisons are the same as in $A$.
To determine whether the increase in intracellular $\mathrm{Na}^{+}$caused the increase in intracellular $\mathrm{Ca}^{2+}$, we removed extracellular $\mathrm{Na}^{+}$ by choline substitution (Fig. 4B). When $\alpha$-LTX was applied to nerve terminals bathed in NCFS (i.e., no $\mathrm{Ca}^{2+}$ or $\mathrm{Na}^{+}$), the $\mathrm{Na}^{+}$ fluorescence decreased $(-16.7 \pm 2 \% ; N, n=3,3)$. The decrease in intracellular $\mathrm{Na}^{+}$was not attributable to dye loss because the $\mathrm{Na}^{+}$ signal increased when extracellular $\mathrm{Na}^{+}$was reintroduced. Thus, unlike results in CFS, increases in the intracellular $\mathrm{Na}^{+}$concentration do not occur when nerve terminals are treated with $\alpha$-LTX in NCFS. When changes in intracellular $\mathrm{Ca}^{2+}$ were measured in NCFS, the effect of $\alpha$-LTX on $\mathrm{Ca}^{2+}$ mobilization was reduced by $70 \%(N, n=4,13$; Fig. $4 B)$. This suggests that $\mathrm{Na}^{+}$influx is necessary for $\mathrm{Ca}^{2+}$ mobilization by $\alpha$-LTX.

Is $\mathrm{Na}^{+}$entry required for $\alpha$-LTX-dependent exocytosis?

To determine whether transmitter release by $\alpha$-LTX still occurred in the absence of extracellular $\mathrm{Na}^{+}$and $\mathrm{Ca}^{2+}$, we could not use electrophysiological techniques because there would have been no $\mathrm{Na}^{+}$-dependent postsynaptic current. Therefore, we measured changes in fluorescence from terminals for which the vesicles had been loaded with FM1-43 by nerve stimulation (see Materials and Methods; Cochilla et al., 1999). In this manner, FM1-43 was taken up into vesicles during endocytosis and was released during exocytosis. When $\alpha$-LTX was applied in NCFS, the nerve terminals, which had accumulated FM1-43 previously, lost most of their fluorescence in $40 \mathrm{~min}$ (Fig. $4 C$ ). Similar results were obtained in two other experiments. This suggests that $\mathrm{Na}^{+}$entry is not required by $\alpha$-LTX to stimulate the fusion of synaptic vesicles.

\section{Relationship between $\mathrm{Ca}^{2+}$ and $\alpha$-LTX-induced transmitter release}

To examine the role of $\mathrm{Ca}^{2+}$ in mediating the effects of $\alpha$-LTX on spontaneous transmitter release, we used the cell-permeant $\mathrm{Ca}^{2+}$ chelator BAPTA-AM to quell changes in intracellular free $\mathrm{Ca}^{2+}$. To maximize the effect of BAPTA-AM at the time of $\alpha$-LTX action, (1) we added an anion pump inhibitor, probenecid (1 mM), to minimize the loss of BAPTA from the cytosol (Ouanounou et al., 1996); (2) we gave a second treatment of BAPTA-AM $15 \mathrm{~min}$ after the first (final concentration $200 \mu \mathrm{M}$ ) to get a longer-lasting effect of the chelator; and (3) we added $\alpha$-LTX at 10 times the normal concentration to hasten the action of the toxin (time to onset, $<2 \mathrm{~min}$ ) $15 \mathrm{~min}$ after the second BAPTA-AM addition. Following these criteria ensured that the effects of $\alpha$-LTX were observed when $\mathrm{Ca}^{2+}$ buffering was at its strongest. In CFS, BAPTA-AM significantly reduced the toxin-induced increase in $\mathrm{Ca}^{2+}$ fluorescence by $\sim 94 \%(N, n=3,3)$ but had no effect on the acceleration of transmitter release $(>300 \mathrm{MEPPs} / \mathrm{sec} ; N, n=2,2$; Fig. 5). The data suggest that $\mathrm{Ca}^{2+}$ released by $\alpha$-LTX from intracellular stores does not play a major role in toxin-induced exocytosis.

\section{DISCUSSION}

\section{$\alpha$-Latrotoxin releases intracellular $\mathrm{Ca}^{2+}$}

The first finding here is that $\alpha$-LTX causes an increase in the intracellular $\mathrm{Ca}^{2+}$ concentration to physiologically significant levels that are sufficient to trigger exocytosis. Because these experi- 

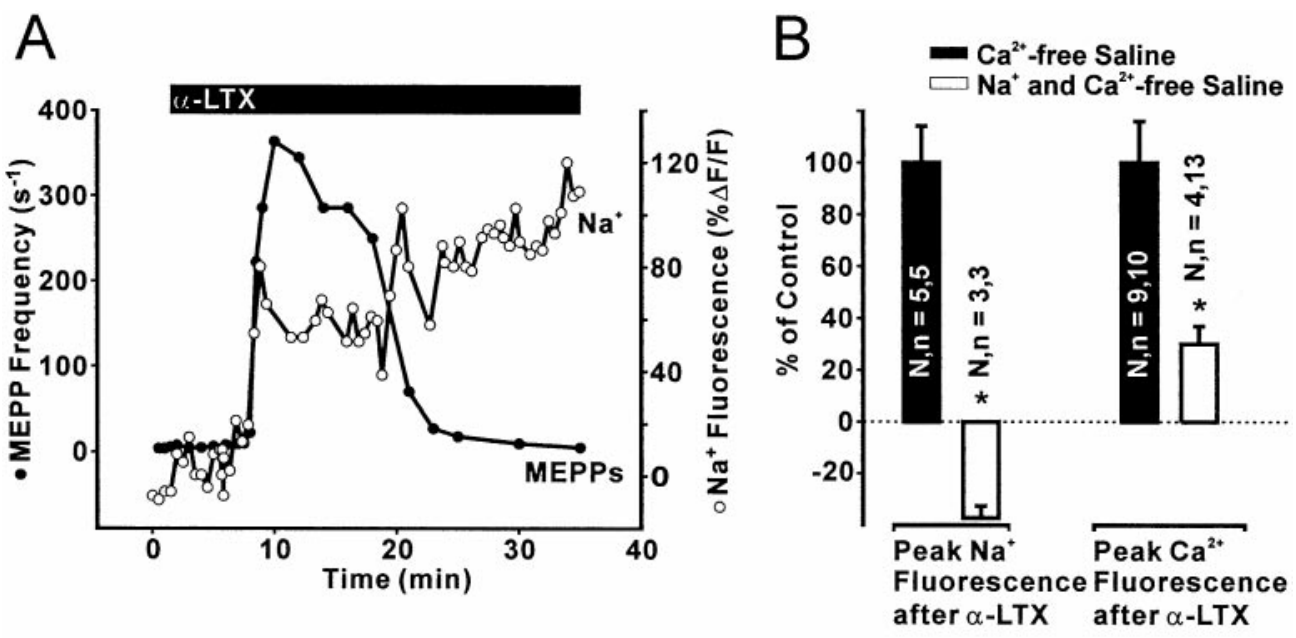

Figure 4. The role of $\mathrm{Na}^{+}$in the action of $\alpha$-LTX. $A, \alpha$-LTX increases intracellular $\mathrm{Na}^{+}$. The graph shows measurements from a simultaneous recording of spontaneous transmitter release (black dots) and $\mathrm{Na}^{+}$fluorescence (white dots) in a motor nerve terminal after treatment with $5 \mathrm{~nm}$ $\alpha$-LTX (bar). Similar results were obtained in two other experiments. $B$, $\alpha$-LTX-induced $\mathrm{Na}^{+}$and $\mathrm{Ca}^{2+}$ signals $(0.5 \mathrm{nM})$ in CFS (black) and NCFS (white) with $4 \mu \mathrm{M}$ TTX. Values were normalized to the effects of the $\alpha$-LTX in CFS and were displayed as a percentage of control. The left and right pairs of bar graphs show the change in intracellular $\mathrm{Na}^{+}$and $\mathrm{Ca}^{2+}$, respectively, after the application of $\alpha$-LTX in CFS and NCFS. Both results in NCFS were significantly different from results in CFS (*). $C, \alpha$-LTX causes exocytosis in the absence of extracellular $\mathrm{Na}^{+}$and $\mathrm{Ca}^{2+}$. The graph shows the changes in vesicular FM1-43 fluorescence after the application of $5 \mathrm{nM} \alpha$-LTX to nerve terminals bathed in NCFS containing $4 \mu \mathrm{M}$ TTX. Similar results were obtained in two other experiments. The insets show pictures of the terminal when $\alpha$-LTX first was applied (5 $\mathrm{min}$ ) and then 15 and 30 min later. Note the disappearance of fluorescent spots that correspond to clusters of labeled vesicles. In these images the contrast has been reversed so that bright areas appear dark.

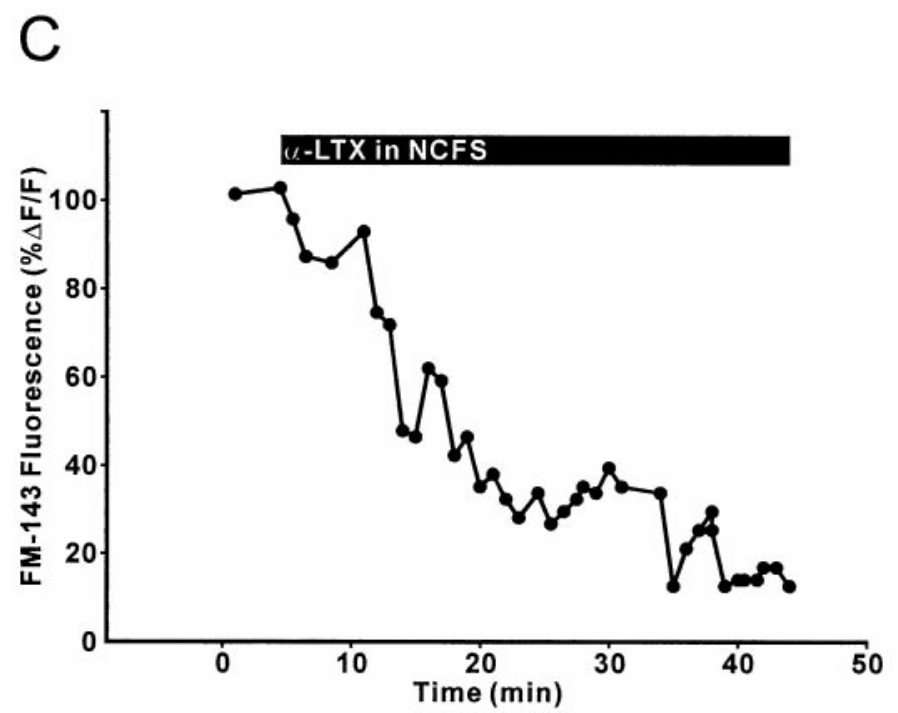

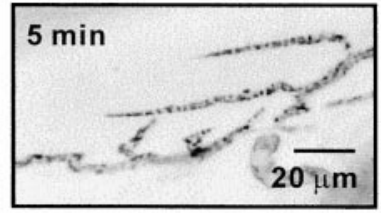
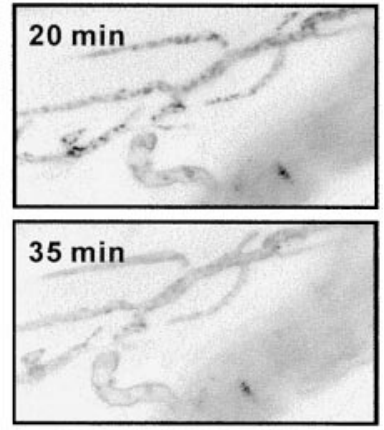

ments were performed in CFS, there must have been a release of intracellular $\mathrm{Ca}^{2+}$ in the motor nerve terminals. It is clear from these results that presynaptic terminals do not lose all of their organelle $\mathrm{Ca}^{2+}$ during a $1 \mathrm{hr}$ incubation in CFS.

\section{The source of released $\mathrm{Ca}^{2+}$}

The next set of experiments revealed some details about the source of this released $\mathrm{Ca}^{2+}$. In nerve terminals, $\mathrm{Ca}^{2+}$ is found in ER, mitochondria, and synaptic vesicles (Meldolesi et al., 1988). Highresolution electron spectroscopic imaging showed that $\mathrm{Ca}^{2+}$ in frog motor nerve terminals was found predominantly in synaptic vesicles and the lumen of smooth ER cisternae (Grohovaz et al., 1996; Pezzati and Grohovaz, 1999). Parts of mitochondria also appear to contain $\mathrm{Ca}^{2+}$ but at a lower concentration than vesicles. In rat brain synaptosomes, $\alpha$-LTX binding to CL1 stimulates PLC that mobilizes $\mathrm{Ca}^{2+}$ from intracellular stores (Davletov et al., 1998). Although $\alpha$-LTX stimulates the breakdown of phosphoinositides (Vicentini and Meldolesi, 1984), this is not critical to the toxin mechanism because an $\alpha$-LTX mutant, which on binding still triggers the breakdown of phosphoinositides, cannot stimulate exocytosis (Ichtchenko et al., 1998). Furthermore, activation of PLC by $\alpha$-LTX in synaptosomes is dependent on the presence of extracellular $\mathrm{Ca}^{2+}$ (Davletov et al., 1998). At the NMJ the source of released $\mathrm{Ca}^{2+}$ by $\alpha$-LTX is unlikely to be the ER, because a PLC inhibitor and a blocker of ER $\mathrm{Ca}^{2+}$ uptake both failed to affect $\alpha$-LTX-induced $\mathrm{Ca}^{2+}$ signals.

Our occlusion experiments showed that $\mathrm{CCCP}$, which is known to release mitochondrial $\mathrm{Ca}^{2+}$, released the same pool of $\mathrm{Ca}^{2+}$ as that released by $\alpha$-LTX. The amount of $\mathrm{Ca}^{2+}$ released by CCCP is similar to that released by $\alpha$-LTX and is sufficient to cause a sustained increase in spontaneous transmitter release from a resting value of $\sim 1$ to $102 \mathrm{MEPP} / \mathrm{sec}$ (Table 1; Alnaes and Rahamimoff, 1975; Zengel et al., 1994). Therefore, the release of $\mathrm{Ca}^{2+}$ by $\alpha$-LTX is likely to reach physiologically significant concentrations.

Mitochondria in lizard motor nerve terminals acquire and release $\mathrm{Ca}^{2+}$ during physiological stimulation (David et al., 1998; David, 1999). In contrast to our results, David (1999) did not report that $\mathrm{CCCP}$ could release mitochondrial $\mathrm{Ca}^{2+}$ although the uptake of $\mathrm{Ca}^{2+}$ was blocked. However, his study used the $\mathrm{Ca}^{2+}$ indicator Oregon green BAPTA-5N, which has much lower affinity than the Oregon green BAPTA-1-dextran (60 $\mu \mathrm{M}$ vs $170 \mathrm{~nm}$ ) used in our experiments. In addition to species differences, another difference between our study and that of David (1999) is that we used 10-fold more CCCP and applied it for a longer period of time; this enhances the possibility of detecting $\mathrm{Ca}^{2+}$ release.

We cannot rule out the possibility that synaptic vesicles, which occupy most of the terminal volume, could release $\mathrm{Ca}^{2+}$ also (for review, see Gonçalves et al., 2000). For instance, Gonçalves et al. (1998) showed that synaptic vesicles can acquire $\mathrm{Ca}^{2+}$ and that uptake is blocked by CCCP. Release of $\mathrm{Ca}^{2+}$ by vesicles was not demonstrated.

\section{Mechanism of $\alpha$-LTX signaling}

$\alpha$-LTX elevated the intracellular $\mathrm{Na}^{+}$concentration as expected from the action of a nonspecific cation channel (Finkelstein et al., 1976) inserted in the presynaptic membrane. In the absence of extracellular $\mathrm{Na}^{+}, \alpha$-LTX caused the loss of $\mathrm{Na}^{+}$, and the release of stored $\mathrm{Ca}^{2+}$ was reduced greatly. Therefore, it appears that 


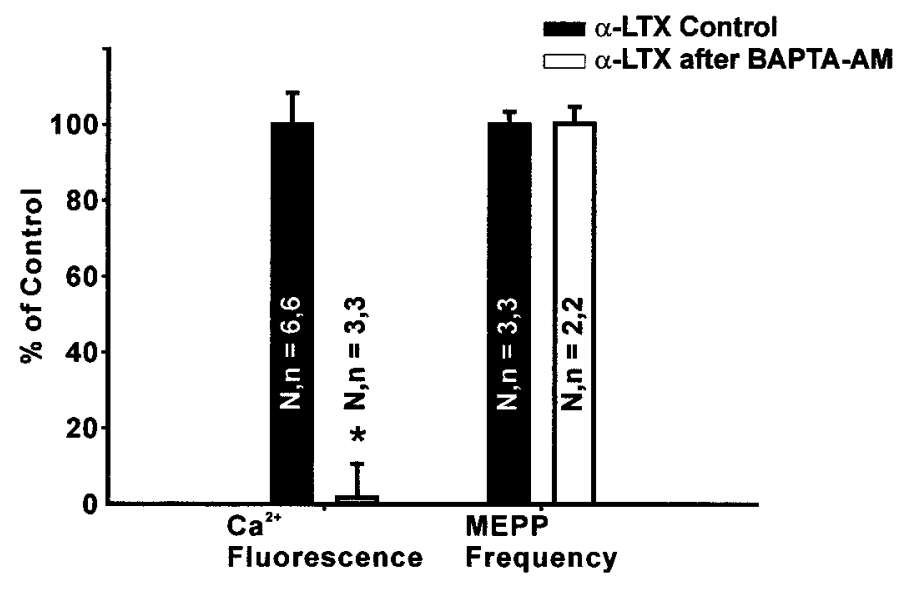

Figure 5. $\alpha$-LTX causes transmitter release with minimal change in the intracellular $\mathrm{Ca}^{2+}$ concentration. Shown are peak $\mathrm{Ca}^{2+}$ fluorescence and peak MEPP frequency achieved by $5 \mathrm{nM} \alpha$-LTX from terminals treated with (white) or without (black) $200 \mu \mathrm{M}$ BAPTA-AM in CFS supplemented with $4 \mu \mathrm{M}$ TTX and $1 \mathrm{mM}$ probenecid. Values for $\mathrm{Ca}^{2+}$ fluorescence and MEPP frequency were normalized and expressed as a percentage of control $(5 \mathrm{nM}$ $\alpha$-LTX in CFS). $\alpha$-LTX-induced $\mathrm{Ca}^{2+}$ fluorescence after BAPTA-AM was reduced significantly as compared with $\alpha$-LTX control $\left(^{*}\right)$.

$\mathrm{Na}^{+}$influx caused by $\alpha$-LTX is primarily responsible for the mobilization of $\mathrm{Ca}^{2+}$, possibly by activating the mitochondrial $\mathrm{Na}^{+} / \mathrm{Ca}^{2+}$ exchanger. Because removing extracellular $\mathrm{Na}^{+}$did not block completely all of the $\mathrm{Ca}^{2+}$ that was released, there may have been an additional mechanism operating.

Black widow spider venom causes nerve terminals to swell in a $\mathrm{Na}^{+}$-dependent manner (Gorio et al., 1978). We confirmed, with observations of terminals filled with fluorescent indicators, that swelling with $\alpha$-LTX occurs in CFS but does not occur in NCFS (data not shown). It is unlikely that swelling is responsible for the effects of $\alpha$-LTX on transmitter release, because it has been shown that the frequency of exocytotic fusion events is reduced considerably as terminals swell (Solsona et al., 1998). Moreover, our experiments in NCFS showed that swelling was not required for $\alpha$-LTX effects.

$\alpha$-LTX increases spontaneous exocytosis in the absence of extracellular $\mathrm{Ca}^{2+}$ provided that $\mathrm{Mg}^{2+}$ or another divalent cation is present (Misler and Hurlbut, 1979; Misler and Falke, 1987). Although our results cannot rule out the possibility that $\alpha$-LTX allows the entry of extracellular $\mathrm{Mg}^{2+}$, it is unlikely that an increase in intracellular $\mathrm{Mg}^{2+}$ is responsible for the $\mathrm{Ca}^{2+}$ signal, because the $\mathrm{Ca}^{2+}$ indicator dye is $\sim 200$ times less sensitive to $\mathrm{Mg}^{2+}$ than $\mathrm{Ca}^{2+}$ (Molecular Probes). Because $\alpha$-LTX probably depolarizes the nerve terminal by increasing membrane conductance to $\mathrm{Na}^{+}$, the extent to which the intracellular $\mathrm{Mg}^{2+}$ concentration could increase would be small. Furthermore, even if $\alpha$-LTX caused the intracellular $\mathrm{Mg}^{2+}$ concentration to increase, $\mathrm{Mg}^{2+}$ is not a good substitute for $\mathrm{Ca}^{2+}$ in triggering transmitter release (Miledi, 1973). The most likely explanation for the requirement of extracellular $\mathrm{Mg}^{2+}$ is that it is required for $\alpha$-LTX to form functional pores in the membrane (Orlova et al., 2000).

\section{Release of $\mathrm{Ca}^{2+}$ is not necessary for $\alpha$-LTX action}

$\alpha$-LTX does not require extracellular $\mathrm{Na}^{+}$to stimulate exocytosis. We showed that $\alpha$-LTX triggers exocytosis of FM1-43-labeled vesicles in the absence of extracellular $\mathrm{Na}^{+}$and $\mathrm{Ca}^{2+}$ (see Fig. $4 C$ ). Under these conditions the intracellular $\mathrm{Ca}^{2+}$ signal is reduced greatly. This supports previous ultrastructural data demonstrating that nerve terminals lose their vesicles after treatment with black widow spider venom in $\mathrm{Na}^{+}$- and $\mathrm{Ca}^{2+}$-free saline (Gorio et al., 1978). Similarly, $\mathrm{Na}^{+}$is not required by $\alpha$-LTX to stimulate the secretion of radiolabeled neurotransmitters from rat brain synaptosomes (Deri et al., 1993; Storchak et al., 1994).

The $\mathrm{Ca}^{2+}$ dependence of $\alpha$-LTX action on exocytosis has been controversial. For instance, in rat brain synaptosomes and adrenal chromaffin cells some studies show that transmitter release by $\alpha$-LTX depends on the presence of extracellular $\mathrm{Ca}^{2+}$ and a rise in intracellular $\mathrm{Ca}^{2+}$ (Davletov et al., 1998; Liu and Misler, 1998; Rahman et al., 1999). However, other studies in these same systems have shown that $\alpha$-LTX does not require any increase in intracellular $\mathrm{Ca}^{2+}$ to stimulate exocytosis (Meldolesi et al., 1984; Michelena et al., 1997). Studies on PC12 cells and $\beta$-pancreatic cells have reached the latter conclusion (Meldolesi et al., 1984; Lang et al., 1998).

At the frog NMJ, $\alpha$-LTX appears to stimulate vesicular exocytosis independently of extracellular $\mathrm{Ca}^{2+}$ and any increase in intracellular $\mathrm{Ca}^{2+}$. When the amplitude of $\mathrm{Ca}^{2+}$ signals was reduced vastly in NCFS (see Fig. $4 C$ ) or after the application of an intracellular $\mathrm{Ca}^{2+}$ chelator (see Fig. 5), the effect of $\alpha$-LTX appeared undiminished. Although we cannot prove that the chelator controlled $\mathrm{Ca}^{2+}$ signals in microdomains at vesicle fusion sites in these experiments, as little as $25 \mu \mathrm{M}$ BAPTA-AM can reduce stimulus-evoked transmitter release in this preparation drastically (Robitaille and Charlton, 1992; Robitaille et al., 1993). It therefore appears that acceleration of exocytosis by $\alpha$-LTX can occur by a mechanism different from that used in normal $\mathrm{Ca}^{2+}$-regulated secretion. This is a plausible conclusion because, in systems in which synaptotagmin function is impaired by peptide injection or genetic mutation, $\mathrm{Ca}^{2+}$-regulated secretion by ionophores and depolarizing agents is impaired, yet acceleration of transmitter release by $\alpha$-LTX remains unaffected (Geppert et al., 1994; Thomas and Elferink, 1998). Similarly, munc13-1, a phorbol ester receptor essential for $\mathrm{Ca}^{2+}$-dependent exocytosis in glutamatergic neurons, is not required for exocytosis by $\alpha$-LTX (Augustin et al., 1999). In contrast, it is possible that $\alpha$-LTX increases the sensitivity of transmitter release to $\mathrm{Ca}^{2+}$. For instance, in permeabilized cells $\alpha$-LTX causes more transmitter release than $\mathrm{Ca}^{2+}$-ionophores or high $\mathrm{K}^{+}$solutions, given the same extracellular $\mathrm{Ca}^{2+}$ concentration (Davletov et al., 1998). We also have seen that the frequency of spontaneous transmitter release with $\alpha$-LTX far exceeds that obtained with $\mathrm{CCCP}$, although the $\mathrm{Ca}^{2+}$ signals produced by both agents are similar.

The action of $\alpha$-LTX contrasts with that of $\alpha$-latrocrustatoxin ( $\alpha$-LCTX), a similar toxin in black widow spider venom. $\alpha$-LCTX also causes increased spontaneous transmitter release in crustacean synapses, but this action requires only the elevation of intracellular $\mathrm{Ca}^{2+}$ concentration subsequent to $\mathrm{Ca}^{2+}$ entry via a pore (Elrick and Charlton, 1999).

In conclusion, our results provide a more complete picture of the actions of $\alpha$-LTX at the frog NMJ, the classic preparation in which $\alpha$-LTX action first was described. Our data show that assumptions about $\mathrm{Ca}^{2+}$ independence of drug and toxin effects in the absence of extracellular $\mathrm{Ca}^{2+}$ must be tested. Experiments that are designed to test hypotheses of $\mathrm{Ca}^{2+}$-independent mechanisms of $\alpha$-LTX action would be confused by the exocytosis triggered by intracellular $\mathrm{Ca}^{2+}$ release. Furthermore, $\alpha$-LTX is used frequently as a tool to obtain $\mathrm{Ca}^{2+}$-independent exocytosis, and the interpretation of these experiments too may be complicated by the release of intracellular $\mathrm{Ca}^{2+}$. The data also show that the main effect of $\alpha$-LTX in the NMJ is not via a $\mathrm{Ca}^{2+}$-dependent mechanism.

\section{REFERENCES}

Alnaes E, Rahamimoff R (1975) On the role of mitochondria in transmitter release from motor nerve terminals. J Physiol (Lond) 248:285-306.

Atwood HL, Charlton MP, Thompson CS (1983) Neuromuscular transmission in crustaceans is enhanced by a sodium ionophore, monensin, and by prolonged stimulation. J Physiol (Lond) 335:179-195.

Augustin I, Rosenmund C, Sudhof TC, Brose N (1999) Munc13-1 is essential for fusion competence of glutamatergic synaptic vesicles. Nature 400:457-461.

Baker PF, Crawford AC (1975) A note of the mechanism by which inhibitors of the sodium pump accelerate spontaneous release of transmitter from motor nerve terminals. J Physiol (Lond) 247:209-226.

Bennett MR (1999) The concept of a calcium sensor in transmitter release. Prog Neurobiol 59:243-277.

Budd SL, Nicholls DG (1996) A reevaluation of the role of mitochondria in neuronal $\mathrm{Ca}^{2+}$ homeostasis. J Neurochem 66:403-411. 
Ceccarelli B, Hurlbut WP (1980) $\mathrm{Ca}^{2+}$-dependent recycling of synaptic vesicles at the frog neuromuscular junction. J Cell Biol 87:297-303.

Clark AW, Mauro A, Longenecker Jr HE, Hurlbut WP (1970) Effects of black widow spider venom on the frog neuromuscular junction. Effects on the fine structure of the frog neuromuscular junction. Nature 225:703-705.

Clark AW, Hurlbut WP, Mauro A (1972) Changes in the fine structure of the neuromuscular junction of the frog caused by black widow spider venom. J Cell Biol 52:1-14.

Cochilla AJ, Angleson JK, Betz WJ (1999) Monitoring secretory membrane with FM1-43 fluorescence. Annu Rev Neurosci 22:1-10.

David G (1999) Mitochondrial clearance of cytosolic $\mathrm{Ca}^{2+}$ in stimulated lizard motor nerve terminals proceeds without progressive elevation of mitochondrial matrix $\left[\mathrm{Ca}^{2+}\right]$. J Neurosci 19:7495-7506.

David G, Barrett JN, Barrett EF (1998) Evidence that mitochondria buffer physiological $\mathrm{Ca}^{2+}$ loads in lizard motor nerve terminals. J Physiol (Lond) 509:59-65.

Davletov BA, Krasnoperov V, Hata Y, Petrenko AG, Sudhof TC (1995) High-affinity binding of $\alpha$-latrotoxin to recombinant neurexin I $\alpha$. J Biol Chem 270:23903-23905.

Davletov BA, Shamotienko OG, Lelianova VG, Grishin EV, Ushkaryov YA (1996) Isolation and biochemical characterization of a $\mathrm{Ca}^{2+}$-independent $\alpha$-latrotoxin-binding protein. J Biol Chem 271:23239-23245.

Davletov BA, Meunier FA, Ashton AC, Matsushita H, Hirst WD, Lelianova VG, Wilkin GP, Dolly JO, Ushkaryov YA (1998) Vesicle exocytosis stimulated by $\alpha$-latrotoxin is mediated by latrophilin and requires both external and stored $\mathrm{Ca}^{2+}$. EMBO J 17:3909-3920.

Deri Z, Bors P, Adam-Vizi V (1993) Effect of $\alpha$-latrotoxin on acetylcholine release and intracellular $\mathrm{Ca}^{2+}$ concentration in synaptosomes: $\mathrm{Na}^{+}-$ dependent and $\mathrm{Na}^{+}$-independent components. J Neurochem 60:1065-1072.

Dreyer F, Peper K (1974) A monolayer preparation of innervated skeletal muscle fibres of the m. cutaneous pectoris of the frog. Pflügers Arch 348:257-262.

Elrick DB, Charlton MP (1999) $\alpha$-Latrocrustatoxin increases neurotransmitter release by activating a calcium influx pathway at crayfish neuromuscular junction. J Neurophysiol 82:3550-3562.

Finkelstein A, Rubin LL, Tzeng MC (1976) Black widow spider venom: effect of purified toxin on lipid bilayer membranes. Science 193:1009-1011.

Geppert M, Goda Y, Hammer RE, Li C, Rosahl TW, Stevens CF, Sudhof TC (1994) Synaptotagmin I: a major $\mathrm{Ca}^{2+}$ sensor for transmitter release at a central synapse. Cell 79:717-727.

Gonçalves PP, Meireles SM, Gravato C, Vale MGP (1998) $\mathrm{Ca}^{2+}-\mathrm{H}^{+}$ antiport activity in synaptic vesicles isolated from sheep brain cortex. Neurosci Lett 247:87-90.

Gonçalves PP, Meireles SM, Neves P, Vale MGP (2000) Methods for analysis of $\mathrm{Ca}^{2+} / \mathrm{H}^{+}$antiport activity in synaptic vesicles isolated from sheep brain cortex. Brain Res Brain Res Protoc 5:102-108.

Gorio A, Rubin LL, Mauro A (1978) Double mode of action of black widow spider venom on frog neuromuscular junction. J Neurocytol 7:193-202.

Grohovaz F, Bossi M, Pezzati R, Meldolesi J, Tarelli FT (1996) High resolution ultrastructural mapping of total calcium: electron spectroscopic imaging/electron energy loss spectroscopy analysis of a physically/ chemically processed nerve-muscle preparation. Proc Natl Acad Sci USA 93:4799-4803.

Henkel AW, Betz WJ (1995) Monitoring of black widow spider venom (BWSV) induced exo- and endocytosis in living frog motor nerve terminals with FM1-43. Neuropharmacology 34:1397-1406.

Ichtchenko K, Khvotchev M, Kiyatkin N, Simpson L, Sugita S, Sudhof TC (1998) $\alpha$-Latrotoxin action probed with recombinant toxin: receptors recruit $\alpha$-latrotoxin but do not transduce an exocytotic signal. EMBO J 17:6188-6199.

Krasnoperov VG, Bittner MA, Beavis R, Kuang Y, Salnikow KV, Chepurny OG, Little AR, Plotnikov AN, Wu D, Holz RW, Petrenko AG (1997) $\alpha$-Latrotoxin stimulates exocytosis by the interaction with a neuronal G-protein-coupled receptor. Neuron 18:925-937.

Lang J, Ushkaryov Y, Grasso A, Wollheim CB (1998) $\mathrm{Ca}^{2+}$-independent insulin exocytosis induced by $\alpha$-latrotoxin requires latrophilin, a G-protein-coupled receptor. EMBO J 17:648-657.

Lelianova VG, Davletov BA, Sterling A, Rahman MA, Grishin EV, Totty $\mathrm{NF}$, Ushkaryov YA (1997) $\alpha$-Latrotoxin receptor, latrophilin, is a novel member of the secretin family of G-protein-coupled receptors. J Biol Chem 272:21504-21508.

Liu J, Misler S (1998) $\alpha$-Latrotoxin-induced quantal release of catecholamines from rat adrenal chromaffin cells. Brain Res 799:55-63.

Longenecker Jr HE, Hurlbut WP, Mauro A, Clark AW (1970) Effects of black widow spider venom on the frog neuromuscular junction. Effects on endplate potential, miniature endplate potential, and nerve terminal spike. Nature 225:701-703.

Meiri H, Erulkar SD, Lerman T, Rahamimoff R (1981) The action of the sodium ionophore, monensin, on transmitter release at the frog neuromuscular junction. Brain Res 204:204-208.

Meldolesi J, Huttner WB, Tsien RY, Pozzan T (1984) Free cytoplasmic $\mathrm{Ca}^{2+}$ and neurotransmitter release: studies on PC12 cells and synaptosomes exposed to $\alpha$-latrotoxin. Proc Natl Acad Sci USA 81:620-624.

Meldolesi J, Volpe P, Pozzan T (1988) The intracellular distribution of calcium. Trends Neurosci 11:449-452.

Michelena P, de la Fuente MT, Vega T, Lara B, Lopez MG, Gandia L, Garcia AG (1997) Drastic facilitation by $\alpha$-latrotoxin of bovine chromaffin cell exocytosis without measurable enhancement of $\mathrm{Ca}^{2+}$ entry or $\left[\mathrm{Ca}^{2+}\right]_{\mathrm{i}}$. J Physiol (Lond) 502:481-496.

Miledi R (1973) Transmitter release induced by injection of calcium ions into nerve terminals. Proc R Soc Lond [Biol] 183:421-425.

Misler S, Falke LC (1987) Dependence on multivalent cations of quantal release of transmitter induced by black widow spider venom. Am J Physiol 253:C469-C476.

Misler S, Hurlbut WP (1979) Action of black widow spider venom on quantized release of acetylcholine at the frog neuromuscular junction: dependence upon external $\mathrm{Mg}^{2+}$. Proc Natl Acad Sci USA 76:991-995.

Narita K, Akita T, Osanai M, Shirasaki T, Kijima H, Kuba K (1998) A $\mathrm{Ca}^{2+}$-induced $\mathrm{Ca}^{2+}$ release mechanism involved in asynchronous exocytosis at frog motor nerve terminals. J Gen Physiol 112:593-609.

Orlova EV, Rahman MA, Gowen B, Volynski KE, Ashton AC, Manser C, van Heel M, Ushkaryov YA (2000) Structure of $\alpha$-latrotoxin oligomers reveals that divalent cation-dependent tetramers form membrane pores. Nat Struct Biol 7:48-53.

Ouanounou A, Zhang L, Tymianski M, Charlton MP, Wallace MC, Carlen PL (1996) Accumulation and extrusion of permeant $\mathrm{Ca}^{2+}$ chelators in attenuation of synaptic transmission at hippocampal CA1 neurons. Neuroscience 75:99-109.

Pezzati R, Grohovaz F (1999) The frog neuromuscular junction revisited after quick-freezing-freeze-drying: ultrastructure, immunogold labeling, and high resolution calcium mapping. Philos Trans R Soc Lond [Biol] 354:373-378.

Rahman MA, Ashton AC, Meunier FA, Davletov BA, Dolly JO, Ushkaryov YA (1999) Norepinephrine exocytosis stimulated by $\alpha$-latrotoxin requires both external and stored $\mathrm{Ca}^{2+}$ and is mediated by latrophilin, G-proteins, and phospholipase C. Philos Trans R Soc Lond [Biol] 354:379-386.

Robitaille R, Charlton MP (1992) Presynaptic calcium signals and transmitter release are modulated by calcium-activated potassium channels. J Neurosci 12:297-305.

Robitaille R, Garcia ML, Kaczorowski GJ, Charlton MP (1993) Functional colocalization of calcium and calcium-gated potassium channels in control of transmitter release. Neuron 11:645-655.

Solsona C, Innocenti B, Fernández JM (1998) Regulation of exocytotic fusion by cell inflation. Biophys J 74:1061-1073.

Sosa MA, Zengel JE (1993) Use of $\mu$-conotoxin GIIIA for the study of synaptic transmission at the frog neuromuscular junction. Neurosci Lett 157:235-238.

Storchak LG, Pashkov VN, Pozdnyakova NG, Himmelreich NH, Grishin EV (1994) $\alpha$-Latrotoxin-stimulated GABA release can occur in $\mathrm{Ca}^{2+}$. free, $\mathrm{Na}^{+}$-free medium. FEBS Lett 351:267-270.

Sugita S, Ichtchenko K, Khvotchev M, Sudhof TC (1998) $\alpha$-Latrotoxin receptor CIRL/latrophilin 1 (CL1) defines an unusual family of ubiquitous G-protein-linked receptors. G-protein coupling not required for triggering exocytosis. J Biol Chem 273:32715-32724.

Thomas DM, Elferink LA (1998) Functional analysis of the C2A domain of synaptotagmin 1: implications for calcium-regulated secretion. J Neurosci 18:3511-3520.

Ushkaryov YA, Petrenko AG, Geppert M, Sudhof TC (1992) Neurexins: synaptic cell surface proteins related to the $\alpha$-latrotoxin receptor and laminin. Science 257:50-56.

Valtorta F, Madeddu L, Meldolesi J, Ceccarelli B (1984) Specific localization of the $\alpha$-latrotoxin receptor in the nerve terminal plasma membrane. J Cell Biol 99:124-132.

Vicentini LM, Meldolesi J (1984) $\alpha$-Latrotoxin of black widow spider venom binds to a specific receptor coupled to phosphoinositide breakdown in PC12 cells. Biochem Biophys Res Commun 121:538-544.

Zengel JE, Sosa MA, Poage RE, Mosier DR (1994) Role of intracellular $\mathrm{Ca}^{2+}$ in stimulation-induced increases in transmitter release at the frog neuromuscular junction. J Gen Physiol 104:337-355. 